\title{
ÚLCERAS GENITAIS PROVOCADAS PELO CITOMEGALOVÍRUS
}

\author{
Ana Marcos-Pinto' MD, João Borges-Costa ${ }^{1,2,3}$ MD, PhD \\ 'Clínica Universitária de Dermatologia de Lisboa, Hospital de Santa Maria, CHLN, Lisboa, Portugal \\ 2Unidade de Investigação em Dermatologia, IMM, Faculdade de Medicina da Universidade de Lisboa, Portugal \\ 3Instituto de Higiene e Medicina Tropical, Lisboa, Portugal
}

RESUMO - A infeção por citomegalovírus é prevalente nos países desenvolvidos. A história natural da doença engloba três fases: primoinfeção (a maioria assintomática), latência e reativação. Em doentes imunossuprimidos, como na transplantação e infeção por VIH, o vírus pode reativar, com manifestações cutâneas, das quais se salienta a ocorrência de úlceras genitais. Nestas, é comum a coinfeção com outros agentes etiológicos, nomeadamente com o vírus herpes simplex, dificultando o diagnóstico diferencial e tornando as lesões mais exuberantes. Neste contexto, torna-se relevante conhecer a patogenia deste vírus, os meios diagnósticos disponíveis, de modo a optimizar a sua abordagem terapêutica.

PALAVRAS-CHAVE - Coinfecção; Doenças dos genitais femininos; Herpes simples; Infecções por citomegalovirus; Úlcera.

\section{GENITAL ULCERS CAUSED BY CYTOMEGALOVIRUS}

ABSTRACT - The cytomegalovirus infection is prevalent in developed countries. The natural history of disease includes three phases: primoinfection (majority is asymptomatic), latency and reactivation. In certain immunosuppressive states, as in the case of transplantation and HIV infection, the virus can reactivate, occurring cutaneous manifestations, of what stands out the occurrence of genital ulcers. In these, co-infection with other etiologic agents is common, particularly with the herpes simplex virus, leading to more severe manifestations and difficulty in the differential diagnosis. In this context, it is relevant to know the pathogenesis of this virus and the diagnostics means available in order to optimize its therapy.

KEY-WORDS - Coinfection; Cytomegalovirus infections; Genital diseases, female; Herpes simplex; Ulcer.

Conflitos de interesse: Os autores declaram não possuir conflitos de interesse. No conflicts of interest.

Suporte financeiro: O presente trabalho não foi suportado por nenhum subsídio ou bolsa. No sponsorship or scholarship granted. Direito à privacidade e consentimento escrito / Privacy policy and informed consent: Os autores declaram que pediram consentimento ao doente para usar as imagens no artigo. The authors declare that the patient gave written informed consent for the use of its photos in this article.

Recebido/Received - Fevereiro/February 2015; Aceite/Accepted - Junho/June 2015

\section{Correspondência:}

Dr. a Ana Marcos-Pinto

Clínica Universitária de Dermatologia de Lisboa - Hospital de Santa Maria

Av. Prof. Egas Moniz

1649-028 Lisboa, Portugal

Email: anaimarcos.pinto@gmail.com

\section{INTRODUÇÃO}

O citomegalovírus (CMV) é um vírus de $A D N$, membro da família Herpesviridae, que inclui, entre outros, os vírus Herpes Simplex (VHS), vírus Varicela-Zoster (VHZ) e Epstein-Barr, sendo morfologicamente semelhante a estes.

A infeção por CMV está amplamente distribuída, afetando cerca de $70-90 \%$ da população mundial.' Nalguns estudos, 30-50\% dos adultos têm anticorpos circulantes; e em alguns grupos, como homossexuais masculinos com ou sem infeção pelo $\mathrm{VIH}$, os anticorpos estão presentes em cerca de $100 \%$ dos casos. ${ }^{2}$

A infeção pode ser transmitida de forma congénita, perinatal (pelo leite materno e secreções maternas infetadas), sexual ou por contato com sangue (transfusão) ou secreções 
que transportam viriões livres ou vírus associado à célula. ${ }^{2-4}$

A infeção primária em pessoas imunocompetentes é muitas vezes assintomática ou apresenta-se na forma de síndrome mononucleósico, com mal-estar geral, febre, faringite, linfoadenopatias e linfocitose atípica. Após esta fase, o vírus torna-se latente nas células endoteliais e pode ser reativado, sob determinadas condições, como estados de imunossupressão, em pacientes transplantados, dialisados, com cancro, infeção por $\mathrm{VIH}$ ou que estejam sob terapêutica imunossupressora, sendo considerado um agente oportunístico importante. As manifestações dermatológicas da infeção por $\mathrm{CMV}$, no entanto, são diagnosticadas com pouca frequência..$^{1-4}$

\section{MATERIAL E MÉTODOS}

Foi efetuada uma revisão bibliográfica baseada em pesquisa na base de dados Medline, de 1990 a 2015 com a introdução dos descritores ["cytomegalovirus" e "genital ulcer"], ["cytomegalovirus" e "herpes simplex virus" e "coinfection"] tendo sido selecionados os artigos que demonstram o papel do CMV nas úlceras genitais e na coinfeção com vírus herpes simplex.

\section{ÚLCERAS GENITAIS POR CITOMEGALOVÍRUS}

As manifestações cutâneas causadas por CMV, quando presentes, assumem diversas formas: pápulas, nódulos, placas verrucosas, vesículas, púrpura e úlceras. A localização destas lesões é variável, mas existe um predomínio na região genitoperineal. $O$ dano celular é resultado, não só da infeção citolítica viral, mas também da resposta imune do hospedeiro, que envolve a ação de linfócitos citotóxicos CD8+ e de citocinas. ${ }^{2,3} \mathrm{O}$ CMV produz vasculite dos pequenos vasos sanguíneos dérmicos, responsável pela formação das lesões purpúricas e ulcerosas, e encontra-se maioritariamente dentro das células mesenquimais (predominantemente nas células endoteliais, mas também pode ser encontrado nos fibroblastos e, por vezes, em macrófagos) e muito raramente em células epiteliais (como nos queratinócitos na epiderme). ${ }^{2-6}$

É descrito que a presença de CMV nas úlceras pode ser o resultado da disseminação hematogénica, da reativação dentro das células endoteliais onde se mantém em latência, ou por autoinoculação através da saliva, urina, fezes ou sémen, localizando-se na maioria dos casos na região genital ou perianal. ${ }^{7}$

As úlceras são descritas na literatura como extensas, com exsudado purulento, não demonstrando tendência para a cura. Podem apresentar semelhanças às úlceras genitais provocadas por vírus herpes simplex nos indivíduos $\mathrm{VIH}$ positivos. ${ }^{2-5}$

A infeção por herpes simplex genital é a maior causa de úlceras genitais em todo o mundo. Nos pacientes com $\mathrm{VIH}, \mathrm{O}$ herpes genital manifesta-se, por vezes, de forma atípica e severa, podendo ocorrer resistência ao tratamento com aciclovir, embora constitua uma situação rara. Estas manifestações exuberantes e severas podem representar infeções concomitantes por outros agentes, nomeadamente, CMV, devendo sempre suspeitar de coinfeção nesse contexto. ${ }^{5,7}$

O papel patogénico desempenhado pelo CMV na patogénese das úlceras cutâneas coinfetadas em indivíduos $\mathrm{VIH}+$ tem sido alvo de controvérsia. Apesar de ser defendido que o agente principal na patogénese é o VHS, alguns estudos concluíram que o CMV desempenha um papel significativo, na manutenção das lesões coinfetadas e na sua cronicidade, baseado na descrição de casos de lesões que melhoraram apenas com terapêutica anti-CMV como o ganciclovir ou valaganciclovir. $5,8-10$

As úlceras por CMV de localização anoretal, mais comuns nos comuns nos homens que têm sexo com homens, são na sua maioria lesões únicas, grandes, profundas, e em alguns casos, podem comprometer o aparelho esfincteriano por vasculite, com consequente incontinência anal, sendo importante o diagnóstico e tratamento precoce. ${ }^{7}$

Alguns estudos sugerem que a deteção de CMV nas lesões cutâneas tem um valor prognóstico importante, visto que constitui, muitas vezes, um marcador de infeção sistémica concomitante ou iminente, tornando-se relevante a pesquisa do antigénio citomegálico no sangue e noutros tecidos como na retina, sendo primordial, se positiva, a instituição de tratamento atempado. Há referência a uma taxa de mortalidade na ordem dos $85 \%$ em seis meses, quando existe infeção cutânea a CMV em indivíduos imunossuprimidos. 8,9,11

\section{VIH E TRANSPLANTADOS}

Como descrito anteriormente, a reativação da infeção por CMV pode ocorrer em condições específicas de imunossupressão como é o caso de doentes transplantados (Fig. 1) e portadores de infeção por VIH (Fig. 2).

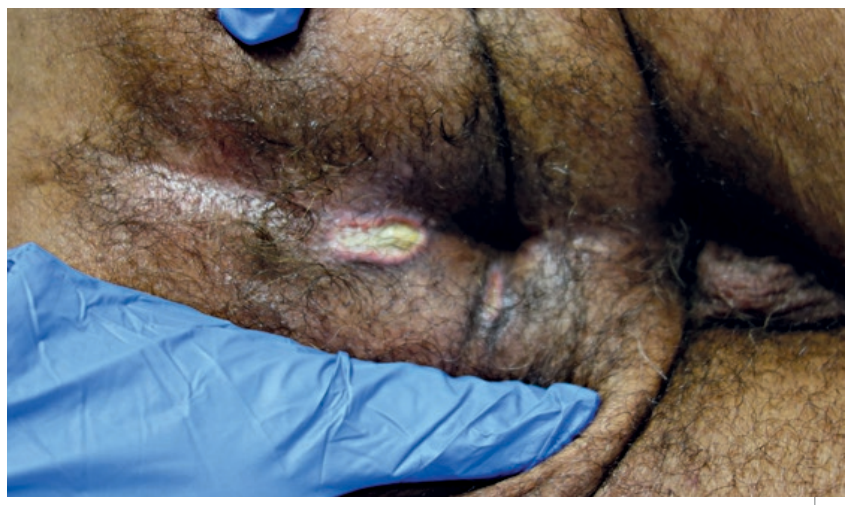

Fig 1 - Placa ulcerada, 2 cm de maior diâmetro, bordos bem limitados e fundo amarelo, com exsudado purulento, na região perianal provocada por CMV em doente com transplante renal. 


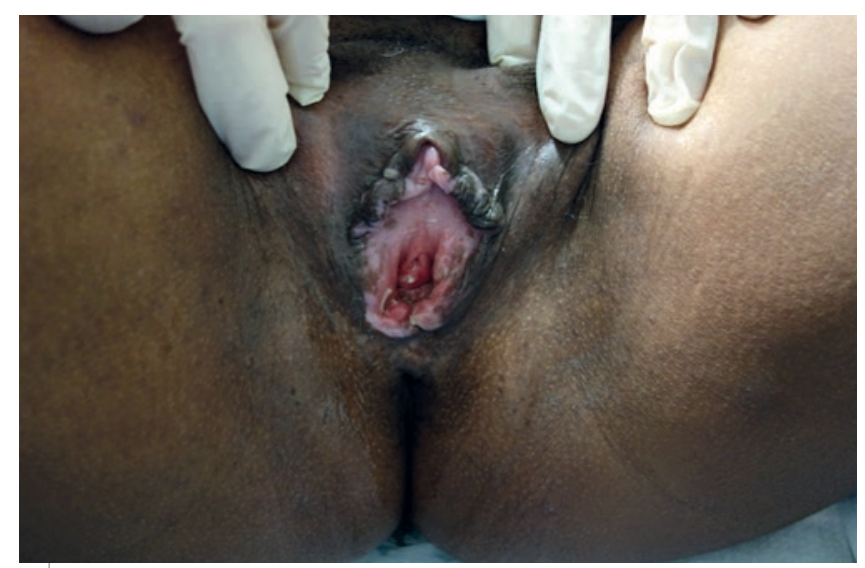

Fig 2 - Úlceras nos pequenos lábios, com edema, eritema perilesional e discreto exsudado amarelo, provocada por CMV em doente $\mathrm{VIH}+$

Nos doentes sujeitos a transplante renal, a reativação é responsável pela doença sintomática, que ocorre dentro de 4-12 meses pós transplante. O CMV é um dos agentes com maior efeito negativo nos recetores de transplante de órgãos sólidos e tem sido implicado na patogénese da rejeição. Por essa razão, regimes quimioprofiláticos contra o CMV (por exemplo, ganciclovir, valganciclovir) têm sido recomendados no primeiro ano pós-transplante. ${ }^{1}$

A infeção por CMV é igualmente comum nos doentes $\mathrm{VIH}$ positivos, embora a sua presença nas lesões cutâneo-mucosas seja raramente descrita. $2,3,5,12$

\section{DIAGNÓSTICO DE INFEÇÃO POR CMV}

No caso de úlceras genitais, outras causas mais comuns devem ser excluídas, incluindo infeção por vírus herpes simplex tipo 1 e 2 e sífilis.

\section{Importância da biópsia no diagnóstico diferencial}

A biópsia auxilia no diagnóstico diferencial. Devem ser retiradas várias amostras do fundo da úlcera, dado que a doença é multifocal. Histologicamente, a presença de células típicas aumentadas $(20-40 \mu)$ com volumosas inclusões intranucleares $(8-10 \mu)$ basofílicas, rodeadas por um halo claro ("olho de corvja") é considerada indicação de doença por CMV. A histologia implica $12 \%$ de falsos negativos e a sensibilidade é aumentada pela utilização de anticorpos monoclonais ou de ensaios de ácidos nucleicos para deteção do antígeno na amostra de tecido. As inclusões intranucleares do CMV podem confundir-se com as do VHS. A diferença entre ambas é que o CMV produz inclusões tanto intranucleares (basofílicas, arredondadas, rodeadas por halo) como intracitoplasmáticas, enquanto o VHS e o VVZ provocam inclusões intranucleares eosinofílicas, sem halo. 2,3,6

\section{Diagnóstico laboratorial}

\section{- Serologia}

A serologia tem pouca utilidade para diferenciar primoinfeção de reativação nos pacientes VIH positivos, dado que ambos os títulos de lgG e lgM podem subir em ambos os períodos. $^{2-5}$

- Cultura

O diagnóstico mais sensível é a cultura realizada a partir dos líquidos ou secreções corporais, que demora ente 1 a 6 semanas. ${ }^{2-5}$

- Imunohistoquímica

A deteção de antigénios de CMV mediante a utilização de anticorpos monoclonais tem sensibilidade idêntica à cultura e especificidade de 100\%, com resultados fiáveis em menos de 24 horas. $^{2-5}$

\section{- Biologia molecular}

A hibridização de ácidos nucleicos identifica fragmentos do genoma viral. Utilizam-se técnicas como hibridação in situ ou amplificação de ADN por reação de polimerase em cadeia $(P C R)$, sendo esta técnica a mais valiosa pela elevada sensibilidade e especificidade. Salienta-se que, com o desenvolvimento das técnicas de biologia molecular, a realização de biópsias com intuito diagnóstico, é muitas vezes evitável, substituindo-se pela pesquisa de material genético destes vírus nas úlceras por PCR. ${ }^{2-5}$ De referir, no entanto, que esta técnica ainda não está disponível em muitos centros hospitalares.

- Outros métodos - Teste de Tzanck

A citologia de Tzanck consiste em método simples e confiável para o diagnóstico de dermatoses virais, parasitárias, autoimunes e tumorais. Relativamente à infeções herpéticas, os achados patognomónicos consistem na presença de grandes queratinócitos multinucleados ("em balão"). O citoplasma é hiperbasófilo, os núcleos são gigantes, e podem conter corpos de inclusão devido à presença de unidades de reprodução virais. Estes achados são, no entanto, transversais a todas as infeções herpéticas, não permitindo a distinção entre os vários membros da família Herpesviridae. ${ }^{13,14}$

\section{TERAPÊUTICA}

As manifestações cutâneas por CMV têm sido tratadas com sucesso com ganciclovir, valganciclovir e foscarnet endovenoso. 2,3,7,9,12

ganciclovir é um derivado do aciclovir, utiliza-se inicialmente na dose de $5 \mathrm{mg} / \mathrm{kg} / 8-12$ horas endovenoso, durante 2-3 semanas. Pode induzir toxicidade medular, inibir a espermatogénese e provocar atrofia da mucosa gastrointestinal. Está contraindicado em casos de neutropénia. 2,3,7,12

O valganciclovir é uma alternativa de administração oral. É rapidamente convertido em ganciclovir a nível intestinal e hepático, sendo a biodisponibilidade 10 vezes superior ao ganciclovir oral (níveis plasmáticos comparáveis à formulação 
endovenosa), com eficácia e efeitos adversos semelhantes. A dose habitual é de $900 \mathrm{mg}$ duas vezes por dia, durante pelo menos 3 semanas. $3,5,7,9,12$

O foscarnet, é uma alternativa quando se verifica resistência aos tratamentos anteriores. É um análogo estrutural do pirofosfato que inibe a $A D N$ polimerase nos vírus $V H S, C M V$ e $\mathrm{VIH}$. Tem uma toxicidade leve, mas pode produzir alterações no metabolismo fosfocálcico ou insuficiência renal ligeira (reverte com hidratação adequada), flebite, anemia, úlceras ou erosões genitais na fase de indução do tratamento.3,6,12

Embora a terapia de indução seguida de manutenção inative o vírus, na ausência de uma boa função do sistema imunitário, pode ser necessário um tratamento prolongado, para evitar recorrências. A profilaxia pode ser efetuada, por exemplo, com $900 \mathrm{mg}$ de valganciclovir, uma vez por dia, durante pelo menos 6 meses.

\section{PONTOS A RETER}

- O CMV é um agente oportunístico importante em situações de imunossupressão (VIH e transplantados).

- As úlceras genitais provocadas por CMV são pouco frequentes.

- Nas úlceras causadas por VHS em doentes imunossuprimidos, com manifestação atípica e grave, refratárias ao tratamento, deve-se suspeitar de coinfeção por CMV.

- A presença de úlceras a CMV pode ser marcador de infeção sistémica, tendo alto valor prognóstico

- A biologia molecular, em desenvolvimento, poderá constituir um dos principais recursos para o diagnóstico.

- O valganciclovir é uma boa opção para tratamento e profilaxia, de administração oral.

\section{REFERÊNCIAS}

1. Garib G, Hughey L, Elmets CA, Cafardi JA, Andea A. Atypical presentation of exophytic herpes simplex virus type 2 with concurrent cytomegalovirus infection: a significant pitfall in diagnosis. Am J Dermatopathol. 2013; 35:371-6.

2. Viglioglia PA. Infección por citomegalovirus atención a sus manifestaciones cutâneas. Act Terap Dermatol. 2007; 30:298.
3. Sewell CA, Anderson JR. Cytomegalovirus disease in the lower female genital tract. AIDS Patient Care STDS. 2001; 15:459-62.

4. Guo R, Gebreab FH, Tang H, Piao Z, Lee S, Perez M. Cutaneous ulcer as leading symptom of systemic cytomegalovirus infection. Case Rep Infect Dis. 2015; 723962.

5. Gouveia Al, Borges-Costa J, Soares-Almeida L, Sacramento- Marques $M$, Kutzner $\mathrm{H}$. Herpes simplex virus and cytomegalovirus co-infection presenting as exuberante genital ulcer in a woman infected with human immmunodeficiency virus. Clin Exp Dermatol, 2014; 39:915-7.

6. Choi Y, Kim J, Jang K, Kim DS, Sim WS, Lee JH, et al. Characteristics of cutaneous cytomegalovirus infection in non-acquired immune deficiency syndrome, immunocompromised patients. Br J Dermatol. 2006; 155:977-82.

7. Lambert EM, Strasswimmer J, Lazova R, Antaya RJ. Cytomegalovirus ulcer. Successful treatment with valganciclovir. Arch Dermatol. 2004; 140:1199-201.

8. Dauden E, Fernandez-Buezo G, Fraga J. Mucocutaneous presence of cytomegalovirus associated with human immunodeficiency virus infection: discussion regarding its pathogenetic role. Arch Dermatol. 2001; 137:443-8.

9. Schoenfeld, J, Cannon, S, Cam, k, Keller M. Cutaneous co-infected cytomegalovirus and herpes simplex virus perigenital ulcers in human immunodeficiency virus patients. J Clin Aesthet Dermatol. 2013; 6:41-3.

10. Moodley M, Chetty R, Moodley J. Vulval cytomegalovirus coexisting with herpes simplex virus in a patient with human immunodeficiency virus infection. BJOG. 2003; 110:1123-4.

11. Toome BK, Bowers KE, Scott GA. Diagnosis of Cutaneous Cytomegalovirus Infection: a review and report of a case. J Am Acad Dermatol. 1991; 24:857-63.

12. Tan $\mathrm{HH}$, Goh CL. Viral infections affecting the skin in organ transplant recipients: epidemiology and current management strategies. Am J Clin Dermatol. 2006; 7:3-29.

13. Brito, M, Arruda D, Roselino A, Tarquínio D, Costa R. Tzanck smears: an old but useful diagnostic tool. An Bras Dermatol. 2009; 84:431-3.

14. Ruocco E, Brunetti G, Vecchio M Del, Ruocco V. The practical use of cytology for diagnosis in dermatology. J Eur Acad Dermatol Venereol. 2011; 25:125-9. 